\title{
AS POLÍTICAS DO MEDO: O SIGNIFICADO DOS DISCURSOS DA EXTREMA-DIREITA POPULISTA
}

IGOR LACERDA

UNIVERSIDADE DO ESTADO DO RIO DE JANEIRO

RIO DE JANEIRO, RIO DE JANEIRO, BRASIL IGORLACERDASA@GMAIL.COM 


\section{AS POLÍTICAS DO MEDO: O SIGNIFICADO DOS DISCURSOS DA EX- TREMA-DIREITA POPULISTA}

WODAK, Ruth. The politics of fear: what right-wing populist discourses mean. London: Sage, 2015.

Linguista austríaca, Ruth Wodak é professora emérita da Universidade de Lancaster e filiada à Universidade de Viena. Nessas duas instituições de ensino, ela desenvolve pesquisas sobre antissemitismo, estudos de gênero, discursos políticos, discursos organizacionais e construção das identidades dos países europeus. A respeito desses temas, foi autora ou coautora de títulos como: Disorders of discourse (1996); The discursive construction of national identity (1999); Discourse and discrimination: rhetorics of racism and antisemitism (2001); The politics of exclusion: debating migration in Austria (2008); The discourse of politics in action: politics as usual (2009) e Methods of critical discourse analysis (2009).

O trabalho mais recente de Ruth Wodak é The politics of fear: what right-wing populist discurses mean, que foi publicado em 2015 pela editora Sage. Neste livro, por meio de uma perspectiva histórico-discursiva, é analisada a trajetória de partidos/políticos populistas de direita na Europa e nos Estados Unidos de 1980 a 2013, bem como suas retóricas racistas, xenofóbicas, nacionalistas e antissemitas. Nos EUA, foi estudado o Partido Republicano, mais especificamente o Tea Party - um grupo conservador formado por republicanos que defendem políticas fiscais ultraliberais e a interpretação da constituição segundo as perspectivas e os preconceitos de 1787, quando foi criada - ato que não levaria em consideração as lutas por direitos de LGBT+1, negros, mulheres, judeus e outros grupos, que eram negligenciados no período. Estima-se que $10 \%$ dos norte-americanos façam parte desse movimento, segundo a autora. Na Europa, ela estuda partidos como UK Indenpendence Party (Reino Unido); British National Party (Reino Unido); Freedom Party of Austria (Austria); Front National (França); Lega Nord (Itália); Alleanza Nazionale (Itália); Five Star Movement (Itália) e Forza Italia (Itália). Mesmo estando

1 A opção pelo uso da sigla LGBT+ vem da explicação do Glossário LGBT+ (COLETIVO AMETISTA UERJ LGBT+, 2019, p. 5): “Inicialmente, a sigla era descrita como GLS, incluindo apenas gays, lésbicas e 'simpatizantes'. Após alguns anos, foram incluídos bissexuais e transgêneros, e a sigla passou a ser LGBT. A adição do + significa a inclusão de diversos grupos que não se encaixam nas outras letras do termo, como assexuais, não binários, genderqueers, intersexos, dentre outros". 
em diferentes países, todos esses partidos são anti-imigração e defendem cortes significativos nas políticas públicas de imigração legal, assim como a superioridade de pessoas caucasianas, heterossexuais/cisgêneras ${ }^{2}$ e não pobres.

Para Wodak, o populismo é definido como uma ideologia que rejeita as antigas formas de fazer política (embora seja mais do mesmo), combinando liberalismo laissez-faire e anti-elitismo. É considerado populismo por causa do seu desejo de dialogar com "homens/mulheres comuns" em oposição às elites - na realidade, a oposição aos empresários capitalistas é ilusória, pois os partidos e os políticos de direita constantemente beneficiam o mercado em detrimento de parte da população. Wodak argumenta que as elites econômicas europeias foram incapazes de restaurar o senso de segurança e desenvolvimento exigidos pelos cidadãos no período pós Segunda Guerra Mundial, e foi justamente nesse contexto de crescente pessimismo, ansiedade e descontentamento que ascendeu o populismo radical de direita.

Para ela, os populistas europeus (tanto de esquerda quanto de direita) consideram que a sociedade está dividida em dois grupos homogêneos e antagônicos: "o povo puro" e a "elite corrupta". Por isso, eles, os populistas, seriam extremamente necessários para defender os interesses do povo, ignorando as demandas das elites. Ou seja, para a autora, os partidos populistas seriam um dos responsáveis pela polarização na política uma vez que adotam discursos e práticas que incentivam a divisão entre o eu/nós e eles/ outros, bons e maus, amigos e inimigos. Como exemplo, esclarece que senadores como Tibério Graco, Gaius Marius, Júlio César e César Augusto eram populistas proeminentes no senado romano, em aproximadamente 44 a.C. Todos eles utilizavam os referendos para driblar as decisões do Senado Romano e apelavam diretamente para o povo com o objetivo de realizar seus próprios desejos (mulheres, escravos e estrangeiros não tinham permissão para votar, revelando que nem todos os grupos faziam parte do povo).

O exemplo dos senadores romanos é interessante porque expõe as manobras realizadas (criação de novos referendos e apelo ao povo) pelos populares para que seus objetivos sejam atingidos, desvendando a relação

2 A opção pelo uso do termo cisgênero vem da explicação presente no Glossário LGBT+ (COLETIVO AMETISTA UERJ LGBT+, 2019, p. 11): "cis vem do latim e significa "do mesmo lado". Cisgênero é toda pessoa que se identifica com o gênero que foi designado a ela". 
entre populismo e autoritarismo. Recorrendo à história, Wodak esclarece que os populistas sempre apelaram ou se associaram a movimentos fascistas de extrema direita. É importante lembrar que Adolf Hitler representava a "vontade do povo", agindo como salvador e mensageiro de uma persona mítica religiosa. A figura do salvador era amplamente explorada pelas retóricas de Hitler, seguindo o seguinte esquema de argumentação: se o perigo é esperado por causa de "X" e se "A" nos salvou no passado, então " $A$ " será capaz de nos salvar novamente. Desde o fim da Segunda Guerra Mundial, as ideologias e estratégias de Hitler circularam e foram adotadas por partidos neonazistas ou extremistas de direita contemporâneos como o FPÖ, o French Front National (FN), o Sweden-Democrats e o British National Party. De acordo com Wodak, embora os ideais nazistas difundidos por Hitler possam ser identificados nos discursos dos partidos populistas de direita na atualidade, as ideias populistas se diferem das nazistas por ter uma abordagem mista e um conjunto contraditório de crenças, estereótipos, atitudes e programas que visam abordar e mobilizar uma gama de segmentos igualmente contraditórios do eleitorado.

Ruth Wodak esclarece que o fenômeno do populismo não é novo, assim como a utilização do medo para justificar e angariar apoio às estratégias dos candidatos de direita. Para ela, a mídia e os políticos americanos sempre apresentaram um cenário de perigo aos eleitores, tornando o medo uma perspectiva dominante. Esse temor começou a ser gerado por objetos e grupos sociais que os americanos temiam, mas com o passar do tempo, depois de muita repetição, tornou-se uma forma de ver a sociedade e os sujeitos que a habitavam. O medo é o sentimento que os cidadãos americanos compartilham e, por grande contribuição de liberais e conservadores, para todos os lados que eles olham é possível identificar temores e figuras que precisam ser controladas e condenadas. Isso ocorre, segundo a autora, porque os sujeitos são confrontados com as perspectivas dicotômicas (eu/ nós contra eles/outros) que servem às ambições de partidos populistas de direita: cenários de ameaça tradicionais e novos; crises reais e exageradas; problemas de segurança exagerados; reportagens da mídia que reproduzem cenários de medo e partidos políticos instrumentalizam todos esses fatores para legitimar políticas excludentes.

É comum que esses partidos utilizem a retórica nacionalista, xenófoba, racista e anti-semita que trabalha principalmente com o medo da mudança, da globalização, da perda de bem-estar, das mudanças climáticas, da mu- 
dança dos papéis de gênero e outros. Quase tudo pode ser construído como uma ameaça para o "nós", que seria o povo homogêneo imaginado dentro de um território bem protegido como os Estados Unidos e a Europa. Depois da Segunda Guerra, esses partidos comumente utilizavam expressões racistas e antissemitas, criando a impressão de que na arena política "vale tudo" e que existem poucas alternativas para estar em segurança - um estado que só seria possível com o enfrentamento de grupos marginalizados. Em 1989, por causa da queda da Cortina de Ferro que dividiu a Europa em Ocidente e Oriente, ocorreu uma constante imigração de pessoas do Oriente Médio para os países europeus, evidenciando a divisão do "Nós" (os verdadeiros austríacos, britânicos, suecos, alemães e dinamarqueses) do "Eles", os forasteiros que vêm de Bahrain, Arábia Saudita, Afeganistão, Catar, Emirados Árabes Unidos, lêmen, Irã, Iraque, Israel, Jordânia, Kuwait, Líbano, Omã, Síria, Turquia. Velhas fronteiras foram desmanteladas e novas foram erguidas: via vistos, testes de idioma e cidadania, uma verdadeira coletânea de regras e regulamentos. Claro que a imigração do Oriente para o Ocidente não é um fenômeno recente: antes de 1989, os "trabalhadores convidados" eram bem-vindos e muitas vezes buscados em seus países de origem; além disso, nos anos 1960, os refugiados que fugiam do sistema político totalitário eram tolerados porque realizavam trabalhos que nenhum ocidental queria assumir. Muitos desses trabalhadores permaneceram na Europa, e conquistaram até a cidadania, porém, a partir de 1989, por influência de partidos de direita, eles começaram a ser identificados como ameaça ao bem-estar, à economia, à cultura e até mesmo à civilização.

Por causa do atentado de 11 de setembro, os muçulmanos foram repentinamente percebidos como um perigo para a segurança em muitos países. Mais restrições à imigração foram rapidamente legitimadas por meio de medidas de segurança apresentadas como necessárias e, portanto, raramente contestadas. A potencial adesão da Turquia à União Europeia evocou veIhas memórias coletivas da vitória dos Habsburgos contra o Império Otomano nos séculos XVI e XVII, gerando o combate do Ocidente cristão contra o Oriente islão. E, finalmente, o alargamento da União Europeia em 2004 levou a uma fusão dos conceitos de refugiados, migrantes e requerentes de asilo: uma imagem inimiga do 'Outro' começou a dominar as lutas e os debates políticos. Esta imagem assumiu muitas formas e formatos locais, sendo um significante compacto que qualquer um pode articular em prol de seus interesses políticos. Além disso, nos EUA, a eleição de Barack Obama para 
presidente desencadeou a ascensão dos movimentos do Tea Party em oposição às políticas econômicas, de segurança e de saúde do governo - muito provavelmente também em reação a um homem negro sentado na Casa Branca. Como será elaborado no livro, não existe uma explicação única para a ascensão dos partidos populistas de direita. Muitos fatores contribuem para esse sucesso, como a renacionalização das tendências nativistas, narrativas e ideologias de fronteira, medos econômicos e as muitas releituras do tempo passado.

A autora ressalta ainda que um dos elementos mais evidentes do sucesso dos políticos de direita é o seu desempenho estratégico e bem trabalhado no palco, nas mídias tradicionais e novas, incluindo as redes sociais, os comícios eleitorais, as coletivas de imprensa e os discursos, sempre orientados para um público específico. Em uma atmosfera de enorme desconfiança da população em relação aos políticos (mais de $60 \%$ não acredita que os governos estejam tomando as decisões corretas, lembra Wodak), os partidos populistas de direita transmitem empatia nas redes sociais, abordam o descontentamento e a raiva em termos simplistas, usam frases de efeito contra as elites (ou os supostos comunistas, no caso do Brasil) e posicionam como salvadores das pessoas que se sentem "deixadas para trás". Para ilustrar seu pensamento, Wodak recorda que, em dezembro de 2014, enquanto estava sendo levada ao aeroporto, um motorista de táxi disse que era como se Nigel Farage, líder do partido populista de direita britânico (UKIP), falasse diretamente com ele nas redes sociais. Embora o motorista tivesse votado no Partido Trabalhista durante toda a sua vida, ele declarou explicitamente estar inclinado a votar no UKIP nas eleições gerais, ocorridas em maio de 2015. Simultaneamente, ele repetiu duas vezes que não endossava ou apoiava qualquer fala ou atitude racista, mas que as relevaria porque Nigel Farage entendia suas preocupações, tinha experiência com o trabalho manual e frequentava bares e restaurantes populares. Quando a pesquisadora disse que Farage era de uma família rica, frequentou escolas públicas e trabalhou como banqueiro, o motorista respondeu que, na verdade, não sabia nada sobre o líder do UKIP, e rebateu: "isso não interfere, ele me entende, ele fala a minha língua”. A história do taxista mostra que os políticos populistas de direita se constroem como "sendo um de nós, homem ou mulher comum", como aquele que vai salvar o "nós" do "eles" que são os oponentes, os estranhos e, de forma mais geral, todas as pessoas perigosas. Estes políticos são treinados para satisfazer as necessidades emocionais e cognitivas 
de seus eleitores, se adaptando a uma variedade de contextos e eventos previsíveis e imprevisíveis.

Com uma visão política profunda, Ruth Wodak revela as estratégias, as retóricas e as supostas verdades dos populistas de direita na contemporaneidade. Por meio do traçado da trajetória dos partidos europeus (que muito se assemelham com os partidos de direita no Brasil) a autora revela que alguns direitistas estão deixando as margens para definir as agendas nacionais e pautar os debates midiáticos. Além disso, enquanto uma importante pesquisadora das retóricas nacionalistas, xenófobas, racistas e anti-semitas, ela aponta como o medo do outro tem servido para esses políticos dialogarem estrategicamente com o seu eleitorado a fim de atrair suas atenções e seus desejos, consolidando preconceitos a respeito das nações, gêneros e corpos. Enfim, este livro é extremamente oportuno uma vez que a política de direita está cada vez mais sendo discutida em diversos espaços nacionais e internacionais, especialmente depois que alguns partidos alcançaram o topo da escalada eleitoral e atraíram seguidores fervorosos e dispostos a realizarem as mais diversas barbaridades para defender seus ideais retrógrados e contrários aos direitos humanos. 


\section{Igor Lacerda}

Doutorando em Comunicação pela Universidade do Estado do Rio de Janeiro (PPGCom UERJ - Bolsista CAPES). Mestre em Comunicação pela Universidade do Estado do Rio de Janeiro. Graduado em Comunicação pela Universidade Veiga de Almeida. Pesquisador no Laboratório de Comunicação, Cidade e Consumo (LACON-UERJ).

E-mail: igorlacerdasa@gmail.com 